\title{
COMPLICATED SKIN AND SOFT TISSUE INFECTIONS IN REMOTE INDIGENOUS COMMUNITIES
}

Running title: Review of Skin Infection Complications

Lauren Thomas, Asha Bowen ${ }^{2,3,4}$,Steven Tong ${ }^{4,5,6}$

${ }^{7}$ Faculty of Medicine Nursing and Health Sciences, Flinders University, Northern Territory, Australia ${ }^{2}$ Infectious Diseases department, Perth Children's Hospital, Western Australia, Australia ${ }^{3}$ Wesfarmers Centre for Vaccines and Infectious Diseases, Telethon Kids Institute, Western Australia, Australia ${ }^{4}$ Menzies School of Health Research, Northern Territory, Australia ${ }^{5}$ Victorian Infectious Disease Service, The Royal Melbourne Hospital, and ${ }^{6}$ Doherty Department University of Melbourne, at the Peter Doherty Institute for Infection and Immunity, Victoria, Australia

Correspondence

Steven Y. C. Tong, Victorian Infectious Diseases

Service, 792 Elizabeth Street, Melbourne, Vic.,

Australia.

Email: steven.tong@mh.orgh.au

\section{ABSTRACT}

The burden and consequences of skin infections for remote living Indigenous people are high. While skin infections are recognised as an antecedent to conditions such as acute rheumatic fever in children, data are limited concerning skin infection complications such as cellulitis, abscesses and osteomyelitis in older children and adults. In a one-year retrospective audit of 439 patients presenting to two remote health clinics, 330/439 (75\%) patients presented with a skin infection and 18 (4\%) developed a complication.

This is the author manuscript accepted for publication and has undergone full peer review but has not been through the copyediting, typesetting, pagination and proofreading process, which may lead to differences between this version and the Version of Record. Please cite this article as doi: 10.1111/imj.14858

This article is protected by copyright. All rights reserved. 
Bacterial skin infections are a common cause of morbidity and mortality in disadvantaged populations ${ }^{1,2}$. Indigenous Australians, particularly those living in remote communities, are amongst those most at risk for skin and soft tissue infections and resulting complications. Numerous clinical audits and research studies have confirmed the high burden of skin infections and hypothesized that early treatment may reduce the risk and subsequent morbidity and mortality associated with acute rheumatic fever (ARF), acute post streptococcal glomerulonephritis (APSGN), and skin related sepsis ${ }^{3}$. There is a gap in our understanding of the overall incidence of complicated skin infections across all age groups.

We aimed to determine the population incidence of complicated skin infections in two remote Aboriginal communities in the Northern Territory, Australia, and to describe these episodes. Human research ethics approval was granted from Menzies (2015-2378) to access the electronic health records of the entire resident population of two remote Aboriginal communities for the 2014 calendar year. We reviewed all clinic presentations to document the number and subsequent complications of skin infections. A detailed description of the methods and general findings has been published ${ }^{4}$. We defined a complication as any skin condition requiring treatment or investigation beyond typical primary care clinical recommendations and included the need for intravenous antibiotics, formal surgical debridement in an operating theatre, or hospital admission. We considered presentations as a single episode of a complicated skin infection if they presented within one month of each other and were described in clinic notes as being in the same anatomical location or if the notes clearly described the infection as a continuation of a previous presentation.

Of 439 residents, 330 (75\%) presented with a skin infection at least once during the year ${ }^{4}$, and 18 of these infections were complicated. In total there were 19 escalation episodes, with one patient requiring hospitalization twice several months apart for the same infection. Of the 18 patients affected, 10 were male. The median age was 25 years with a range of 4-72 years; six patients were below the age of 18 years, including one patient below five, and four patients were aged over 50 years.

Infected wounds were the most common complicated skin infection (12/19) with antecedents including dog and human bites, trauma, and a post-operative wound. Abscesses accounted for 5/19 and impetigo 2/19 cases. The two cases of impetigo occurred in primary school aged children. Fourteen patients had microbiology results from skin swabs recorded. Methicillin-resistant Staphylococcus aureus (MRSA) was detected in 8/14. Of the 19 cases, 16 required intravenous antibiotics, with five of these provided at the remote clinic. Patients were seen between one and 12 (mean five episodes of care) times in the clinic for the same infection.

Fifteen patients were referred to a regional hospital for further investigations or treatment with 14 requiring hospital admission and two a transfer to a tertiary hospital. Mean length of hospitalization was 10 days (range $2-$ 35 days). The complications included osteomyelitis $(n=6), \operatorname{APSGN}(n=2)$, and need for surgical debridement $(n=6)$ (Figure 1). No cases of ARF were recorded.

\section{DISCUSSION}


In addition to the high general burden of skin infections presenting to the remote health linic $^{4}$, we describe a remarkably high rate of complicated infections that often necessitated hospitalization. The dominant pathogen associated with complicated infections was MRSA rather than Group A Streptococcus and most complications occurred in the adult population.

Among the 439 residents, six cases of osteomyelitis equates to a population incidence of $>1,300$ cases per 100,000 person years (95\% confidence interval 617-3,026). In contrast, the estimated incidence of osteomyelitis in the United States is 22 cases per 100,000 person years ${ }^{5}$. Similarly, two cases of APSGN equates to a population incidence of 460 cases per 100,000 person years (95\% Cl 114-1816). The estimated Incidence rates of APSGN in developing nations is 9 cases per 100,000 person years 6 . These incidence estimates in remote communities are likely to fluctuate by year and community, and confidence intervals are large due to sampling from a small population. However, the estimates are broadly in keeping with larger population based studies of complicated skin and soft tissue infections ${ }^{7}$, invasive staphylococcal ${ }^{8}$ and streptococcal infections $^{9}$, and osteomyelitis ${ }^{10}$ presenting to the tertiary hospitals in the Northern Territory.

There are significant costs associated with the hospitalisations required for these complicated skin and soft tissue infections. For the residents in these two communities, the collective length of hospital stay for complicated skin infections was 138 days for 14 patients. Hospital stay costs alone would be in excess of $\$ 270,000$ (at an estimated $\$ 1,938$ per day in the Northern Territory ${ }^{11}$ ). Additional health system costs include retrieval and transfer costs and follow up care.

We identified MRSA associated in almost $60 \%$ of complicated skin and soft tissue infections. This finding is in keeping with other studies from the Northern Territory and highlights the growing public health issue of MRSA infections in remote and Aboriginal communities in Australia $2,7,12,13$. Accordingly, non $\beta$-lactam antibiotic agents such as trimethoprim-sulphamethoxazole may be the most appropriate treatment options to cover both $S$. pyogenes and MRSA ${ }^{14,15}$.

A limitation of this audit is that only one of several electronic health records in use in the NT was assessed. With high population mobility ${ }^{16}$, patients may have also been seen at other clinics or self-referred to hospital for investigation of complications. As such, these results may under-estimate the true burden. Similarly, if the referred hospital did not complete a discharge summary and the patient did not present to the clinic post discharge, the episode of escalation would not be included. The audit only included two communities, with a small population of 439. Detailed patient information on housing conditions and co-morbidities was not collected, and as such, conclusions were unable to be drawn regarding risk factors for skin infection complications.

This audit of remote clinical care reveals three key findings: complications of skin and soft tissue infections affected $4 \%(18 / 439)$ of the population in remote NT Indigenous communities with an attendant high cost burden; MRSA was the most common pathogen detected; and skin and soft tissue infections are a significant cause of clinic activity for remote health care workers. Health promotion activities, training of health care workers in early recognition and treatment of skin infections and ultimately attention to the social determinants of health are all needed to reduce this burden. The STOP trial currently underway in the Kimberely seeks to comprehensively address these to reduce skin infections and subsequent complications ${ }^{17}$. 


\section{FIGURES}

Table 1

\begin{tabular}{|l|l|}
\hline Skin Infection Complication & Number of People Affected (Percentage) \\
\hline Osteomyelitis & $6(32 \%)$ \\
\hline Sepsis & $1(5 \%)$ \\
\hline Melioidosis & $1(5 \%)$ \\
\hline Debridement Needed & $6(32 \%)$ \\
\hline Cellulitis & $3(16 \%)$ \\
\hline Acute Step. Glomerulonephritis & $2(10 \%)$ \\
\hline Total & $18(100 \%)$ \\
\hline
\end{tabular}

Table 1 - Distribution of complicated skin and soft tissue infections 


\section{REFERENCES}

1. Miller LG, Eells SJ, David MZ, Ortiz N, Taylor AR, Kumar N, et al. Staphylococcus aureus. Clinical Infectious Diseases. 2015;60(5):753-63.

2. Tong SYC, McDonald MI, Holt DC, Currie BJ. Global Implications of the Emergence of Community-Associated Methicillin-Resistant Staphylococcus aureus in Indigenous Populations. Clinical Infectious Diseases. 2008;46(12):1871-8.

3. Bailie RS, Stevens MR, McDonald E, Halpin S, Brewster D, Robinson G, et al. Skin infection, housing and social circumstances in children living in remote Indigenous communities: testing conceptual and methodological approaches. BMC Public Health. 2005;5:128-.

4. Thomas L, Bowen AC, Ly M, Connors C, Andrews R, Tong SYC. Burden of skin disease in two remote primary healthcare centres in northern and central Australia. Internal Medicine Journal. 2019;49(3):396-9.

5. Osteomyelitis [Internet]. StatPearls Publishing. 2019. Available from:

https://www.ncbi.nlm.nih.gov/books/NBK532250/.

6. Post-Streptococcal Glomerulonephritis [Internet]. University of Oklahoma Health Sciences Center. 2016. Available from: https://www.ncbi.nlm.nih.gov/books/NBK333429/.

7. Macmorran E, Harch S, Athan E, Lane S, Tong S, Crawford L, et al. The rise of methicillin resistant Staphylococcus aureus: now the dominant cause of skin and soft tissue infection in Central Australia. Epidemiology and infection. 2017;145(13):2817-26.

8. Tong Steven Y. C. BE, Lilliebridge R, Cheng A, Spasova-Penkova Z, Holt D, Giffard P, McDonald M, Currie B, Boutlis C. Community-Associated Strains of Methicillin-Resistant Staphylococcus aureus and Methicillin-Susceptible S. aureus in Indigenous Northern Australia: Epidemiology and Outcomes. Journal of Infectious Disease 2009;199:1461-70.

9. Engelman D, Hofer A, Davis JS, Carapetis JR, Baird RW, Giffard PM, et al. Invasive Staphylococcus aureus Infections in Children in Tropical Northern Australia. Journal of the Pediatric Infectious Diseases Society. 2014;3(4):304-11.

10. Brischetto A, Leung G, Marshall CS, Bowen AC, Munoz M. A Retrospective Case-Series of Children With Bone and Joint Infection From Northern Australia. Medicine. 2016;95(8).

11. Australian Public Hospitals Cost Report 2013-2014 Round 18: Independent Hospital Pricing Authority; 2014. Available from: https://www.ihpa.gov.au/sites/default/files/publications/nhcdc-round18.pdf.

12. Tong SYC, Bishop EJ, Lilliebridge RA, Cheng AC, Spasova-Penkova Z, Holt DC, et al. Community-associated strains of methicillin-resistant Staphylococcus aureus and methicillin-susceptible $S$. aureus in indigenous Northern Australia: epidemiology and outcomes. The Journal Of Infectious Diseases. 2009;199(10):1461-70.

13. Bowen AC, Daveson K, Anderson L, Tong SY. An urgent need for antimicrobial stewardship in Indigenous rural and remote primary health care. Med J Aust. 2019;211(1):9-11.e1.

14. Bowen AC, Lilliebridge RA, Tong SYC, Baird RW, Ward P, McDonald MI, et al. Is Streptococcus pyogenes Resistant or Susceptible to Trimethoprim-Sulfamethoxazole? Journal of Clinical Microbiology. 2012;50(12):4067-72. 15. Bowen AC, Carapetis JR, Currie BJ, Fowler V, Jr., Chambers HF, Tong SYC. Sulfamethoxazole-Trimethoprim (Cotrimoxazole) for Skin and Soft Tissue Infections Including Impetigo, Cellulitis, and Abscess. Open forum infectious diseases. 2017;4(4):ofx232. 
16. Taylor A, Carson D. Indigenous Mobility and the Northern Territory Emergency Response. People and Place. 2009;17:29-38.

17. Mullane MJ, Barnett TC, Cannon JW, Carapetis JR, Christophers R, Coffin J, et al. SToP (See, Treat, Prevent) skin sores and scabies trial: study protocol for a cluster randomised, stepped-wedge trial for skin disease control in remote Western Australia. 2019;9(9):e030635.

This article is protected by copyright. All rights reserved. 


\section{ABSTRACT}

The burden and consequences of skin infections for remote living Indigenous people is high. While skin infections are recognised as an antecedent to conditions such as acute rheumatic fever in children, data are limited concerning skin infection complications such as cellulitis, abscesses and osteomyelitis in older children and adults. In a one-year retrospective audit of 439 patients presenting to two remote health clinics, 330/439 (75\%) patients presented with a skin infection and 18 (4\%) developed a complication. 


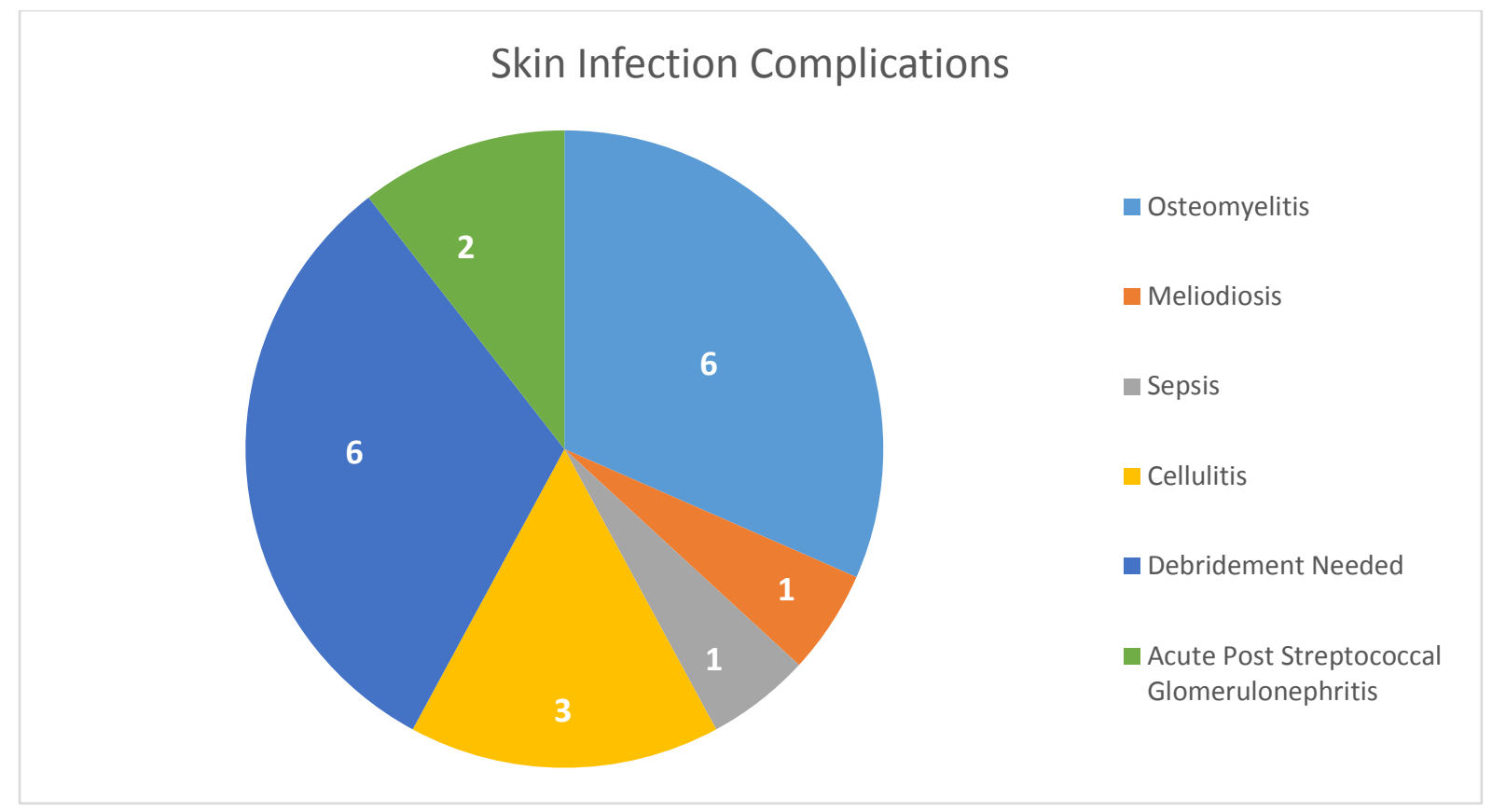

Figure 1 - Distribution of complicated skin and soft tissue infections $(n=18)$ as mutually exclusive categories. 


\begin{tabular}{|l|l|}
\hline Skin Infection Complication & Number of People Affected (Percentage) \\
\hline Osteomyelitis & $6(32 \%)$ \\
\hline Sepsis & $1(5 \%)$ \\
\hline Melioidosis & $1(5 \%)$ \\
\hline Debridement Needed & $6(32 \%)$ \\
\hline Cellulitis & $3(16 \%)$ \\
\hline Acute Step. Glomerulonephritis & $2(10 \%)$ \\
\hline Total & $18(100 \%)$ \\
\hline
\end{tabular}

IMJ_14858_table1.JPG

This article is protected by copyright. All rights reserved. 


\section{COMPLICATED SKIN AND SOFT TISSUE INFECTIONS IN REMOTE INDIGENOUS COMMUNITIES}

Running title: Review of Skin Infection Complications

Lauren Thomas' ${ }^{1}$ Asha Bowen ${ }^{2,3,4}$,Steven Tong ${ }^{4,5,6}$

${ }^{1}$ Faculty of Medicine Nursing and Health Sciences, Flinders University, Northern Territory, Australia ${ }^{2}$ Infectious Diseases department, Perth Children's Hospital, Western Australia, Australia ${ }^{3}$ Wesfarmers Centre for Vaccines and Infectious Diseases, Telethon Kids Institute, Western Australia, Australia ${ }^{4}$ Menzies School of Health Research, Northern Territory, Australia ${ }^{5}$ Victorian Infectious Disease Service, The Royal Melbourne Hospital, and ${ }^{6}$ Doherty Department University of Melbourne, at the Peter Doherty Institute for Infection and Immunity, Victoria, Australia

\section{Correspondence}

Steven Y. C. Tong, Victorian Infectious Diseases

Service, 792 Elizabeth Street, Melbourne, Vic.,

Australia.

Email: steven.tong@mh.orgh.au

This article is protected by copyright. All rights reserved. 


\section{University Library}

\section{- M M N E R VA A gateway to Melbourne's research publications}

Minerva Access is the Institutional Repository of The University of Melbourne

Author/s:

Thomas, L;Bowen, AC;Tong, SYC

Title:

Complicated skin and soft tissue infections in remote indigenous communities

Date:

2020-06-01

Citation:

Thomas, L., Bowen, A. C. \& Tong, S. Y. C. (2020). Complicated skin and soft tissue infections in remote indigenous communities. INTERNAL MEDICINE JOURNAL, 50 (6), pp.752-754. https://doi.org/10.1111/imj.14858.

Persistent Link:

http://hdl.handle.net/11343/275812 